- Article -

\title{
Silicon Chemical Oxide Growth by a Novel Wet Treatment in Aqueous Chlorine Solutions
}

\author{
Marius CHEMLA, ${ }^{\text {a* }}$ Didier LEVy, ${ }^{\mathrm{c}}$ Sébastien PETITDIDIER, ${ }^{\mathrm{c}}$ \\ François ROUELLE, ${ }^{\mathrm{a}}$ and Sandrine ZANNA ${ }^{\mathrm{b}}$
}

\author{
aLaboratoire d'Electrochimie, LI2C, Université P. \& M. Curie (Paris, France) \\ "Laboratoire Physico-Chimie des Surfaces. ENSCP (Paris, France) \\ 'STMicroelectronics R \& D Center (38920 Crolles, France)
}

Received October 27, 2003 ; Accepted February 5, 2004

\begin{abstract}
For the wet cleaning of silicon surfaces, a few new reactants, such as ozone dissolved in UPW, have been proposed to replace the original RCA process using $\mathrm{H}_{2} \mathrm{O}_{2}$ solutions. In the present work we describe, for the first time, the mechanism of silicon surface oxidation by dilute solutions of elemental chlorine. Upon reaction with this highly oxidizing agent, the open circuit potential shifted immediately to positive values, the effect being identical for both $n$ - and p-type $\mathrm{Si}$ substrates. The surface transformation was firstly investigated by electrochemical impedance spectroscopy which showed successive semicircles representing $\mathrm{RC}$ equivalent circuits, revealing a gradual growth of an insulating layer. XPS recordings demonstrated unequivocally the formation of a pure and uniform chemical oxide layer, the possible contamination by $\mathrm{Cl}$ element being negligible. The analysis of the charge transfer reaction by voltammetry led to the conclusion that the exchange between the semiconductor and the solution involved positive holes. The reduction current, at a negative bias potential, was extremely small with p-type $\mathrm{Si}$ as a consequence of a depletion layer appearancc. On the contrary, in n-type substrates, an accumulation region was formed, so that the electric field, as high as $10^{7} \mathrm{~V} \mathrm{~cm}-1$, will promote a conduction mode through the insulating oxide layer. This novel technique of surface treatment seems promising with respects to the economy and environmental requirements, and also for the possible subsequent growth of multi-layer high-k dielectric structures.
\end{abstract}

Key Words : Silicon (Oxide, Wet Treatment, Impedance, Chemical Oxide, High-k Dielectrics

\section{Introduction}

The production of integrated circuits for the development of microelectronics continually requires a chemical surface treatment of the wafers at various steps in the production. The most important demand in the cleaning processes is the achievement of a flat surface completely free of any kind of defects, structure defects, contamination by impurities, adhesion of foreign nanoparticles. ${ }^{1)}$ As the size of the elemental components is always decreasing and the economy of the processing becomes more stringent, the transformations induced by these treatments are subject to extremely strict requirements.

At present time the most widespread technology is a wet processing, called RCA, initiated by Kern and Puotinen. ${ }^{2}$ It mainly consists of a first oxidation step of the bare wafer surface in an alkaline medium made of an ammonia plus hydrogen peroxide mixture (APM) called SC1 ( Standard Clean \#1). This first treatment results in the rapid growth of an $\mathrm{Si}$ oxide layer whose surface charge contributes to eject the adherent nanoparticles. But the alkaline properties of this solution presents the inconvenience of a substrate etching which is not negligible at the nanoscopic scale, and accordingly it induces an unfavorable effect on surface microroughness. ${ }^{3,4}$ ) The second step corresponds to the transformations induced by an acidic reactant called $\mathrm{SC} 2$, a solution made of a mixture of $\mathrm{HCl}$ with hydrogen peroxide (HPM). The main advantage of this treatment is that it excludes the residual traces of metal contaminants, and makes the surface oxide layer more compact and insulating. ${ }^{5)}$

Recently, driven by the relentless progress towards submicron ULSI technology, there is a high interest in developing low temperature processing techniques. When oxidation is concerned the use of ozonized aqueous solutions is nowadays expanding since it leads almost instantaneously to the generation of a compact protecting $\mathrm{Si}$ oxide layer. Originally suggested in 1993 by Ohmi et al ${ }^{6)}$ for oxide growth in aqueous solutions, the method was simultaneously extended by Kazor and Boyd $^{7}$ for Si oxidation in the gaseous phase.

Ozone dissolved in ultrapure water (UPW) generates an active radical in the course of its self-decomposition. ${ }^{6}$ ) The strong oxidizing character of this radical promotes a rapid attack of all organic impurities, and also accelerates the growth of an oxide layer on the wafer surface. Since self-decomposition of ozone in ultrapure water proceeds in a short time, the concentration of oxygen radicals is very high and the oxidation power is stronger than in other chemicals. It follows that a thick oxide layer is rapidly grown in the ozone-injected pure water, and moreover, after computing the surface roughness from AFM scanning, it was concluded that the oxide was grown uniformly on the wafer surface.

Since several years the formulation of the wet treat- 
ment solutions have continually been optimised in order to meet the requirements for the miniaturization of the circuits at the submicron level, and also for the economic and environmental factors. Recently Zhang ${ }^{81}$ published a wide analysis on the various oxidation methods and the corresponding properties of the generated insulating layers. Nevertheless, most of the techniques used at present time show some inconvenience which can be summarized as follows: i) during the treatment by $\mathrm{SC} 1$ solution the etching rate of the $\mathrm{Si}$ substrate is far from being negligible and results in an unfavourable effect on the surface microroughness, ${ }^{i}$ ii) the oxidizing reactivity of the acidic SC2 solution is rather poor and a uniform oxide layer is hardly obtained with this reactant when used alone, iii) the reaction of the $\mathrm{Si}$ surface with aqueous solutions of ozone starts abruptly and cannot be maintained under control. It leads rapidly to a compact oxide which is hardly compatible with the future generations of circuits involving multilayer dielectric insulators.

As a result, it was concluded that the wafer cleaning process presently requires drastic improvements ${ }^{9)}$ to keep all process parameters perfectly under control. The cleaning solutions should preferably be used at low temperature. $^{6)}$

Another important requirement for a regulated growth of the oxide layer is the necessary control of surface bonds on top of the interface to adapt to the formation of a high-k dielectric film. ${ }^{10)}$ Haukka et al.$^{11)}$ showed that, in the atomic layer chemical vapor deposition (ALCVD), the incoming precursor reacts with the top surface bonds on the substrate, and concluded that control of this surface oxide layer is a crucial factor for a high quality ALCVD dielectric layer. It was observed that, for the formation of most ALCVD layers, hydroxyl groups (-Si-OH) should be present on the top surface prior to the exposure of the reactant vapors. ${ }^{12)}$

In the present work we describe the first results obtained in a novel research program dedicated to the investigation of alternative redox couples for a controlled oxidation process of the silicon substrate surface. The purpose of this project is to identify new cleaning solutions well fitted to the actual requirements for the fabrication of nanoscale integrated circuits. The program was directed in the study of dilute aqueous solutions of elemental halogen, $\mathrm{Cl}_{2}, \mathrm{Br}_{2}$, or $\mathrm{I}_{2}$, which should be considered as valuable reactants from the economic and environmental point of view. ${ }^{13)}$ No previous publication dealing with such cleaning solutions was found in the literature. Indeed, published experiments using halogen elements concerned only plasma, ${ }^{14)}$ or high temperature ${ }^{15)}$ $\mathrm{Si}$ etching in the gaseous phase. In this paper, we describe first results obtained in the wet treatment of $\mathrm{Si}$ wafers by dilute solutions of elemental chlorine gas dissolved in pure water.

\section{Experimental}

The work was mainly carried out using p-type $\mathrm{Si}$ wafers, $\mathrm{CZ}$ grown (Czochralski method ${ }^{16)}$ ) boron doped $\approx 10^{16}$ at $\mathrm{cm}^{-3}$, resistivity $9-18 \Omega \mathrm{cm},(100)$ oriented, 200 $\mathrm{mm}$ diameter, from the production line of STMicroelec- tronics Company. Alternatively, other experiments were carried out with n-type $\mathrm{Si}$ wafers phosphorus doped, resistivity $8-20 \Omega \mathrm{cm}$. The study was mainly conducted either by electrochemical techniques to characterize the rate of the electrochemical reaction and the build-up of the chemical surface oxide, or X-ray photoelectron spectroscopy (XPS) to analyse the chemical shift of the elemental components and evaluate the thickness of the oxide layer. In all experiments, the $\mathrm{Si}$ samples were beforehand cleaned in a mixture of concentrated sulfuric acid and hydrogen peroxide (SPM) at $100^{\circ} \mathrm{C}$ during $10 \mathrm{~min}$ utes. After thorough rinsing with UPW, the samples were cleaned by a $1 \% \mathrm{HF}$ in $1 \mathrm{M} \mathrm{HCl}$ solution thus leading to a pure oxide-free silicon hydrophobic surface stabilized by Si-H terminal bonds.

For the electrochemical characterization of the process, wafer samples were cut in $3.5 \times 3.5 \mathrm{~cm}^{2}$ size. The measurements were conducted in an electrochemical cell which allows a good control of several parameters. The scheme and the performance of this cell were described in our previous publication. ${ }^{17)}$ We recall that it was designed so that the sample was protected against external light and the deleterious effect of confinement near the seal ring was negligible. The input impedance of our devices being more than $10^{10} \Omega$ the electrical contact on the back side of the sample was made of a pasted Ga-In alloy connected to a gold foil. Then the resistance of the interface $\mathrm{Au} / \mathrm{Si}$ was less than 1 to $5 \Omega$ depending on the substrate. The counter electrode was a small platinum plate $1 \times 1 \mathrm{~cm}^{2}$. The reference was a saturated calomel electrode connected to the electrolyte by means of a bridge made of a Teflon capillary tube filled with a $\mathrm{KCl}$ solution in agarose gel. The electrolyte was a $0.1 \mathrm{M} \mathrm{HCl}$ solution containing dissolved elemental chlorine $\mathrm{Cl}_{2}$ at the concentration of $2 \times 10^{-2} \mathrm{M}$. The room temperature was almost constant at $22 \pm 1^{\circ} \mathrm{C}$.

Firstly, a series of electrochemical measurements such as the variation of the open circuit potential (OCP) as a function of time, and the determination of the electron transfer characteristics of the redox reaction of chlorine by linear voltammetry, were obtained with a Tacussel Radiometer Analytical PGS 201T potentiostat, driven by an IBM PC microcomputer using the Voltamaster software. The Electrochemical Impedance Spectrometry (EIS) measurements were undertaken with an EG\&G PAR potentiostat connected to an impedance analyser Solartron 1260. The sinusoidal signal amplitude was $\pm 10 \mathrm{mV}$ in a frequency range from $10^{5}$ to $10^{-2} \mathrm{~Hz}$. The equivalent circuits best fitting the experimental data were modelled as loops involving a constant phase element (CPE) imaginary term in parallel with a purely ohmic resistance. The quantitative values of these components were derived from the complete set of numerical data processed by a non-linear least square fit using the Boukamp software. ${ }^{18)}$ From these measurements, it was demonstrated that the CPE behaves as a pure capacitor with a standard deviation less than $10^{-3}$. Both $R$ and $C$ components of the equivalent circuit representing the semiconductor/oxide/ electrolyte (SOE) structure were computed from the experimental data. But, as shown previously, ${ }^{19)}$ the capaci- 
tance term was extremely sensitive to the substrate potential vs electrolyte. Then, to characterize the oxide layer growth and structure and to avoid any change in the surface properties, we mainly focussed on the resistance component of the circuit at zero direct current density, less than a few $\mathrm{nA} \mathrm{cm}^{-2}$ (OCP). The recording of a complete EIS diagram generally needed about 15 minutes. During the wet chemical treatment by chlorine aqueous solutions the change of OCP vs time was very rapid. For this reason the EIS diagrams were often recorded in the frequency range $10^{4}$ to $10^{-1} \mathrm{~Hz}$ which was obtained after about 5 minutes.

The growth of a silicon oxide layer was also monitored by XPS analysis, in order to identify the appearance of combined $\mathrm{Si}$ atoms together with the increase of oxygen element, and to check the absence of possibly trapped chloride ions. The samples $1.5 \times 1.5 \mathrm{~cm}^{2}$ of hydrophobic Si were simply treated by a solution of $\mathrm{Cl}_{2}$ in UPW at the concentration of $2 \times 10^{-2} \mathrm{M}$, during 2 and 20 minutes at room temperature. After thorough rinsing with UPW, the samples were transferred into the high vacuum chamber $\left(P=10^{-8} \mathrm{~Pa}\right)$ of a VG Escalab Mk II X-ray photoelectron spectrometer using an $\mathrm{Al} \mathrm{K} \alpha$ radiation. The calibration of the instrument for the binding energies was obtained with $\mathrm{Cu} 2 \mathrm{p}_{3 / 2}(932.9 \mathrm{eV})$ and $\mathrm{Au} 4 \mathrm{f}_{7: 2}(84.0 \mathrm{eV})$ respectively. The accuracy of the energy measurements being $0.1 \mathrm{eV}$, the $\mathrm{Si} 2 \mathrm{p}, \mathrm{O} 1 \mathrm{~s}$ and $\mathrm{Cl} 2 \mathrm{p}$ core level spectra were recorded at a pass energy of $20 \mathrm{eV}$ with $0.1 \mathrm{eV}$ steps. The detection angle was normal to the surface. The energy range from 90 to $110 \mathrm{eV}$ was mainly investigated to resolve the $\mathrm{Si} 2 \mathrm{p}$ level between the $\mathrm{Si}^{0}$ state representing the bulk substrate atoms and the $\mathrm{Si}^{1+}$ state which is assigned to the stoichiometric $\mathrm{SiO}_{2}$ oxide. Moreover the density of $\mathrm{O}$ atoms was evaluated from the intensity of the XPS peak at $533 \mathrm{eV}$ corresponding to the $\mathrm{O}$ 1s core level. In a first approximation, the oxygen $\mathrm{O}$ to $\mathrm{Si}^{4+}$ atomic ratio was calculated from the areas $I_{\mathrm{i}}$ of the corresponding peaks and the cross sections $\sigma_{\mathrm{i}}$ for the electron emission after X-ray capture, using the following equation:

$$
\mathrm{n}_{\mathrm{O}} / \mathrm{n}_{\mathrm{Si}}\left(\mathrm{SiO}_{2}\right)=\left(I_{\mathrm{O}} / \sigma_{\mathrm{O}}\right)\left(\sigma_{\mathrm{Si} 2 \mathrm{p}} / I_{\mathrm{Si} 2 \mathrm{p}}\right)
$$

where $\sigma_{\mathrm{o}}$ and $\sigma_{\mathrm{Si} 2 \mathrm{p}}$ are respectively the cross sections for $\mathrm{O} 1 \mathrm{~s}$ and for the combined part of $\mathrm{Si} 2 \mathrm{p}$ level. ${ }^{20)}$

Finally, the region near $200.5 \mathrm{eV}(\mathrm{Cl} \mathrm{2p})$ was also investigated to detect any alleged presence of adsorbed chloride ions, although the very low emission intensity was lost in the background emission at $201 \mathrm{eV}$ due to another transition of $\mathrm{Si} 2 \mathrm{p}$ core level due to the plasmon effect corresponding to the energy loss by electrons interacting with the atoms near the surface.

\section{Results}

In accordance with our experience on the electrochemical properties of silicon surfaces, ${ }^{21)}$ the very first results of this investigation were the recordings of the sudden rise of the open circuit potential following the introduction of the oxidizing reagent. Figure 1 shows very clear results obtained in the following simple experi- ments: after positioning the hydrophobic silicon sample, the electrochemical cell was filled with $15 \mathrm{~cm}^{3}$ degassed $0.1 \mathrm{M} \mathrm{HCl}$ solution, and the OCP was recorded during ca. 5 minutes. In this condition, the OCP of $\mathrm{Si}$ in contact with degassed $\mathrm{HCl}$ solution is not perfectly well defined since no charge exchange reaction occurs, it reaches a reproducible value near $-0.3 \mathrm{~V}$ vs SCE. Then $5 \mathrm{~cm}^{3}$ of a solution made of UPW containing $8 \times 10^{-2} \mathrm{M}$ elemental $\mathrm{Cl}_{2}$ obtained by bubbling the gas generated by chemical reaction of $\mathrm{HCl}$ with $\mathrm{KMnO}_{4}$. The final solution contains $2 \times 10^{-2} \mathrm{M} \mathrm{Cl}_{2}$ in a $0.075 \mathrm{M} \mathrm{HCl}$ solution. A rapid rise of the OCP is immediately observed leading to a limiting value near $+0.4 \mathrm{~V}$ vs SCE. Naturally, we observed in several other experiments that the rate of the potential rise and the final value of the OCP depended on the $\mathrm{Cl}_{2}$ concentration. But the most interesting conclusion of these experiments is the almost identical behaviour of $p$ type and n-type Si substrates when the experimental conditions are identical.

These results were complemented by records of voltammetric scans of both $\mathrm{p}$ - and $\mathrm{n}$-type $\mathrm{Si}$ at the end of the treatment by $\mathrm{Cl}_{2}$ solutions. For clarity, we present first on Fig. 2 the voltammogram obtained with p-type $\mathrm{Si}$ alone. In general the current density is small, a few nanoamps per $\mathrm{cm}^{2}$, although the standard redox potential of $\mathrm{Cl}_{2} / \mathrm{Cl}^{-}$couple is equal to $+1.116 \mathrm{~V}$ vs SCE. The measured current $j=j_{+}+j_{-}$rises sharply when the potential is more positive than the OCP value $(+0.4 \mathrm{mV}$ vs $\mathrm{SCE})$. This shows a rather fast anodic oxidation reaction

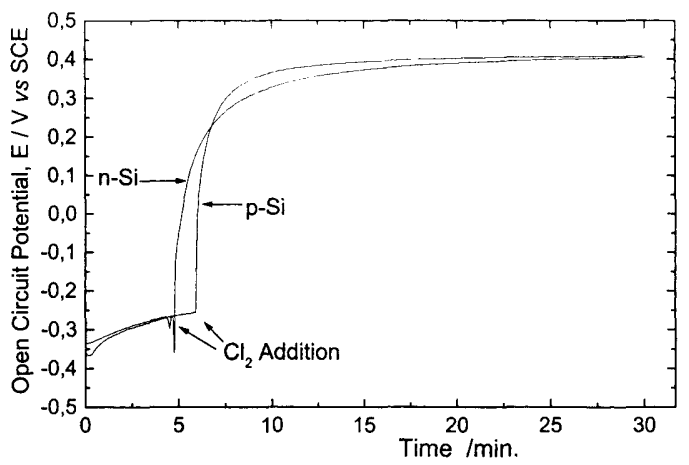

Fig. 1 Variation of the Open Circuit Potential, in the dark, upon addition of $\mathrm{Cl}_{2}$ aqueous solution. The behaviour of $\mathrm{n}$ and p-type $\mathrm{Si}$ is quite identical.

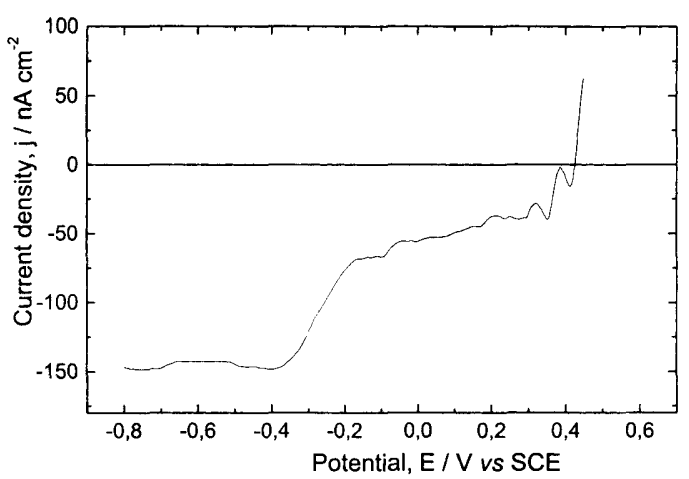

Fig. 2 Current/voltage diagram for $\mathrm{Cl}_{2}$ electrochemical reaction in the dark, at a p-type $\mathrm{Si}$ oxidized surface. 


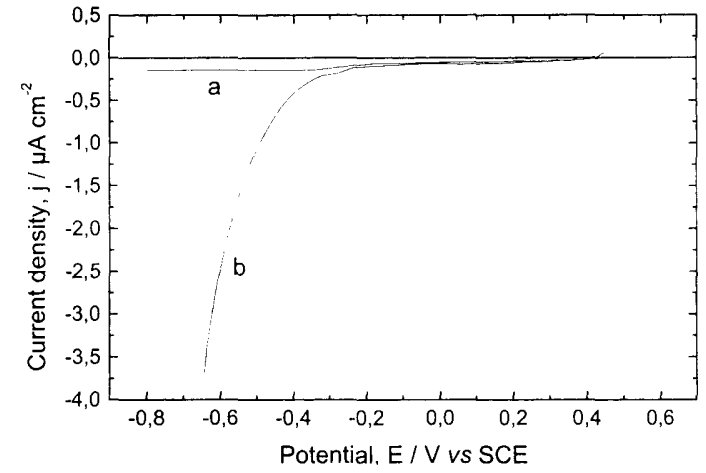

Fig. 3 Current/voltage diagrams in the dark for $\mathrm{Cl}_{2}$ electrochemical reduction. a: at p-type $\mathrm{Si}$ oxidized surface, $b$ : at $\mathrm{n}$ type $\mathrm{Si}$ oxidized surface.

which could be easily understood for a p-type silicon. The reduction current remains extremely low mainly due to the insulating oxide layer, and just a small increase appears between -0.2 and $-0.4 \mathrm{~V}$ vs SCE leading to a plateau at $-150 \mathrm{nA} \mathrm{cm} \mathrm{cm}^{-2}$ until $-1.0 \mathrm{~V}$ vs SCE. On the other hand, Fig. 3 shows a superposition of the voltammograms obtained with p-type and n-type silicon. In a wide range of potential between +0.45 to $-0.35 \mathrm{~V}$ vs $\mathrm{SCE}$, the current density is low, and rises suddenly for more negative potentials only with n-type $\mathrm{Si}$. This fact could suggest the involvement of electrons $\mathrm{e}^{-}$in the charge transfer reaction.

Electrochemical experiments were ended with electrochemical impedance spectroscopy. Figure 4 represents an interesting illustration of the oxide growth at the interface of p-type $\mathrm{Si}$ with a dilute $10^{-3} \mathrm{M} \mathrm{Cl}_{2}$ in $0.1 \mathrm{M} \mathrm{HCl}$ solution. In these conditions the reaction was slow enough to permit the records of the diagrams which were obtained at 15 minutes time intervals. We previously observed ${ }^{22)}$ similar growth phenomena during the treatment of p-type $\mathrm{Si}$ with $\mathrm{SC} 1$ and $\mathrm{SC} 2$ oxidizing solutions. In the case of p-type $\mathrm{Si}$ the shift of the OCP to positive values makes the semiconductor space charge to be in the accumulation regime, so that the observed diagrams can be attributed to the dielectric properties of the SOE junction. The data processing of after analysis of the diagrams in Fig. 4 led to the values reported on Table 1.

The diagrams obtained with n-type silicon wafers were quite different. In fact, as the OCP rises towards positive values vs $\mathrm{SCE}$, the space charge turns to be in the depletion regime. In this case the EIS diagrams are constituted of two separate $R C$ circuits as indicated in our previous publications. ${ }^{19,23)}$ Figure 5 shows such diagrams, where the semicircle is representative of the depletion layer $R C$ circuit, the corresponding value of the capacitance being equal to $\approx 1.5 \times 10^{-8}$ Farads. Only the steep rise of imaginary impedance at the low frequency end of the diagram is assigned to the interfacial oxide layer. The diagrams are close each other because the $\mathrm{Cl}_{2}$ solution was concentrated, $2 \times 10^{-2} \mathrm{M}$, and the steady regime was almost reached. However, it is interesting to indicate that the diameter of semicircle $b$ is somewhat larger than for $a$. This means that the OCP for $b$ is more positive than for $\mathrm{a}$, and that the resistance of the depletion layer

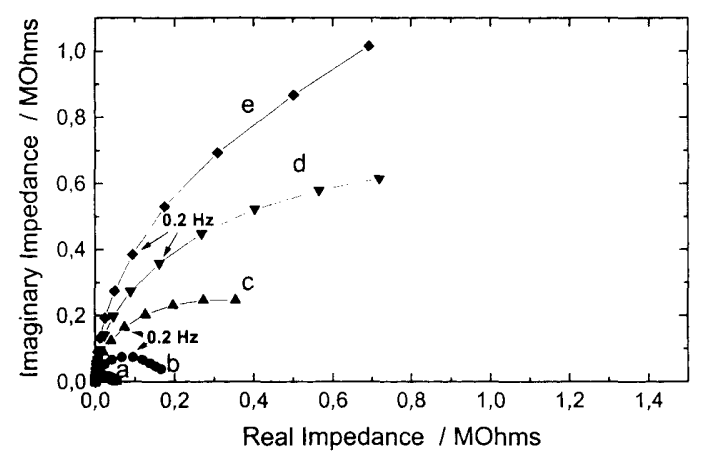

Fig. 4 Successive Electrochemical Impedance diagrams, in the dark, for p-type $\mathrm{Si}$ in contact with a diluted solution of $\mathrm{Cl}_{2}$ in aqueous $1 \mathrm{M} \mathrm{HCl}$ solution, at different time intervals. a: 10 min, b: $30 \mathrm{~min}$, c: $50 \mathrm{~min}, \mathrm{~d}: 70 \mathrm{~min}$, e: $90 \mathrm{~min}$.

Table 1 Variations of $R \mathrm{p}$ and $C$ of $\mathrm{Si}$ surface oxide produced by reaction with $\mathrm{Cl}_{2}$ solution as a function of time.

\begin{tabular}{lccccc}
\hline Curve on Fig. 4 & $\mathrm{a}$ & $\mathrm{b}$ & $\mathrm{c}$ & $\mathrm{d}$ & $\mathrm{e}$ \\
\hline Time, minutes & 10 & 30 & 50 & 70 & 90 \\
\hline $\begin{array}{l}\text { Surface Resistance, } \\
\Omega \mathrm{cm}^{2}\end{array}$ & $1.2 \times 10^{5}$ & $4.8 \times 10^{5}$ & $1.4 \times 10^{6}$ & $3.3 \times 10^{6}$ & $5.7 \times 10^{6}$ \\
$\begin{array}{l}\text { Capacitance, } \\
\mu \mathrm{F} \mathrm{cm} \mathrm{cm}^{-2}\end{array}$ & 0.72 & 0.60 & 0.58 & 0.55 & 0.55 \\
\hline
\end{tabular}

was increased. ${ }^{19 \prime}$ Moreover, the rise of imaginary component at the low frequency end of the curve is steeper than for $b$ curve. It means that the oxide resistance was increased between these two records. Nevertheless, the processing of the whole set of data using the Boukamp software led to the evaluation of the $R C$ components for the oxide, namely $R \approx 5 \times 10^{6} \Omega \mathrm{cm}^{2}$ and $C \approx 1.2 \mu \mathrm{F} \mathrm{cm}-2$. It is worth to indicate that these properties are closely linked to the oxide layer. The main reason is that the resistance $R$ was observed to grow rapidly with time along with the oxidation reaction. Moreover the very high value $5 \times 10^{6} \Omega$ was obtained in spite of the presence of dissolved $\mathrm{Cl}_{2}$. When the electrochemical cell was rinsed and filled with degassed $\mathrm{HCl}$ the value of $R$ was increased to $10^{7}-10^{8} \Omega \mathrm{cm}^{2}$.

Finally, the composition and the thickness of the generated oxide layer was determined by XPS measurements. First a general spectrum in the whole useful

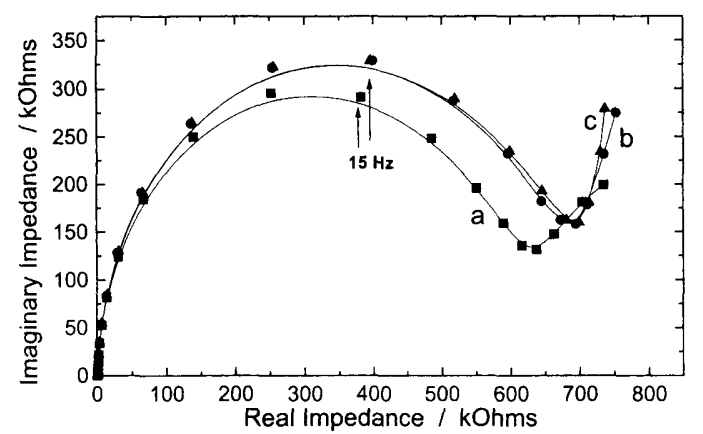

Fig. 5 Successive Electrochemical Impedance diagrams, in the dark, for n-type $\mathrm{Si}$ in contact with a diluted solution of $\mathrm{Cl}_{2}$ in aqueous $1 \mathrm{M} \mathrm{HCl}$ solution, at different time intervals. a: 15 min, b: 30 min, c: 45 min. 
Table 2 Atomic percentage of surface elements after cleaning with a $2 \times 10^{-2} \mathrm{M}$ chlorine aqueous solution during 20 $\mathrm{min}$ at room temperature.

\begin{tabular}{ccccccc}
\hline Element & $\mathrm{Si}^{0}$ & $\mathrm{Si}^{\mathrm{x}}$ & $\mathrm{O}$ & $\mathrm{C}$ & $\mathrm{Cl}$ & Equivalent $\mathrm{SiO}_{2}$ Thickness \\
\hline 56.4 & 6.5 & 26.3 & 10.3 & 0.5 & $4.7 \mathrm{~A}$
\end{tabular}

range of energy was recorded and showed the main visible lines corresponding to $\mathrm{O} 1 \mathrm{~s}, \mathrm{C} 1 \mathrm{~s}, \mathrm{Si} 2 \mathrm{~s}$ and $\mathrm{Si} 2 \mathrm{p}$.

After processing of the experimental data, the results obtained from XPS analysis of the chemically oxidized $\mathrm{Si}$ surface are summarized in Table 2 .

The $\mathrm{C} 1 \mathrm{~s}$ line was rather small, less than the $\mathrm{Si} 2 \mathrm{p}$ line by a factor of 5 , and was classically attributed to adsorbed $\mathrm{CO}_{2}$ or hydrocarbon molecules. We report on Fig. 6 the $\mathrm{Si} 2 \mathrm{p}$ lines obtained respectively with a "bare" silicon substrate i.e. treated by a $\mathrm{HF}+\mathrm{HCl}$ solution, and with a sample after oxidation in the $\mathrm{Cl}_{2}$ solution during 20 minutes at room temperature. It can be seen that the "bare" sample exhibited only one line at $99.5 \mathrm{eV}$ associated to elemental $\mathrm{Si}$ written $\mathrm{Si}^{0}$. The oxidized samples exhibited a sccond peak at $103.3 \mathrm{eV}$ which is representative of the stoichiometric $\mathrm{SiO}_{2}$ compound, written $\mathrm{Si}^{4+}$. Accounting for the instrumental resolution, no other contribution which could be assigned to intermediate $\mathrm{Si}$ oxidation states $^{24}$ was observed after decomposition of the core level signal. In order to evaluate the thickness of the surface oxide layer, an angular analysis of the ratio of signal intensities corresponding to the oxidized and elemental silicon species was undertaken and fitted to a model based on an uniform structure of the layer, using the simplified equation:

$$
\begin{aligned}
I\left(\mathrm{Si}^{\mathrm{ox}}\right) / I\left(\mathrm{Si}^{\mathrm{j}}\right)= & D\left(\mathrm{Si}^{\mathrm{ox}}\right) \lambda\left(\mathrm{Si}^{\mathrm{ox}}\right) / D\left(\mathrm{Si}^{0}\right) \lambda\left(\mathrm{Si}^{0}\right) \\
& \left\{\exp \left(d / \lambda\left(\mathrm{Si}^{\mathrm{ox}}\right) \sin \theta-1\right\}\right.
\end{aligned}
$$

Where $I(i)$ is the peak intensity of species i, $D$ at $\mathrm{cm}^{-3}$ is the atomic density of the element, $\lambda$ is the mean free path of the electron in the phase, and $\theta$ is the detection angle. By modelling the experimental results with eq. (2) it was concluded that the oxide layer was uniform and was equivalent to a $4.7 \AA$ thick $\mathrm{SiO}_{2}$ layer.

Another interesting information obtained from XPS spectra is the analysis of $\mathrm{O} 1 \mathrm{~s}$ which gives a well-defined line at $533 \mathrm{eV}$. But the determination of the $\mathrm{O} / \mathrm{Si}^{\mathrm{ox}}$

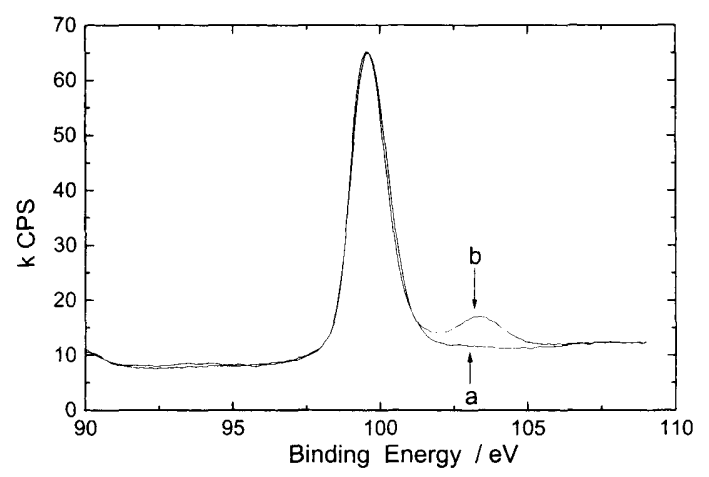

Fig. $6 \mathrm{Si} 2$ p core levels obtained by XPS at the $\mathrm{Si} / \mathrm{SiO}_{2}$ interface, in the 90-110 eV energy range. a) $\mathrm{Si}$ substrate after $\mathrm{HF}$ $+\mathrm{HCl}$ treatment, b) Oxidized surface by $0.02 \mathrm{M} \mathrm{Cl}_{2}$ in UPW.

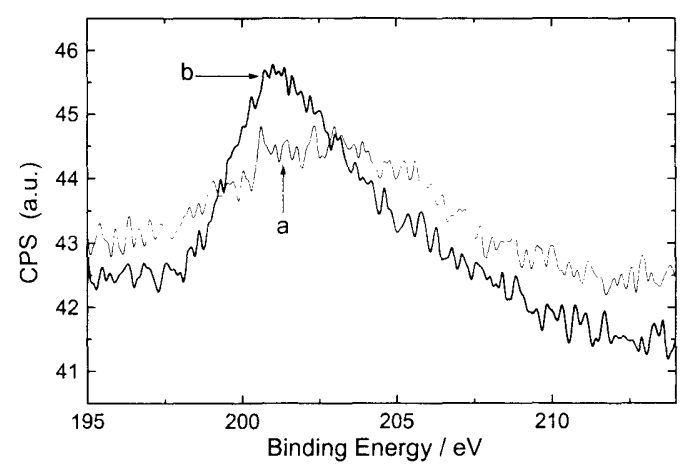

Fig. 7 XPS diagram at oxidized p-type Si surface in the 195$215 \mathrm{eV}$ energy range for the detection of $\mathrm{Cl} 2 \mathrm{p}$ core level. a) $\mathrm{Si}$ substrate after $\mathrm{HF}+\mathrm{HCl}$ treatment, b) Oxidized surface by $0.02 \mathrm{M} \mathrm{Cl}_{2}$ in UPW.

atomic ratio leads to a value near 4 instead of the predicted value 2 for $\mathrm{SiO}_{2}$, and furthermore the $\mathrm{O}$ 1s peak is also observed in "bare" $\mathrm{Si}$ samples. This excess was easily attributed to adsorbed $\mathrm{H}_{2} \mathrm{O}$ molecules, since the energy level of $\mathrm{O} 1 \mathrm{~s}$ is also positioned at $533 \mathrm{eV}$. The important consequence of this measurement is that the insulating layer growing on the $\mathrm{Si}$ surface is a more or less hydrated silicon oxide.

In fact, we necessarily checked for the possible existence of $\mathrm{Cl}$ atoms in this layer. Figure 7 was recorded in the spectral region near $200.5 \mathrm{eV}$ associated with the $\mathrm{Cl} 2 \mathrm{p}$ core emission. The signal which could be assigned to the $\mathrm{Cl}$ atoms is largely lost in the background due to the plasmon effect on $\mathrm{Si}$ electron emission at $201 \mathrm{eV}$. The main conclusion of this experiment is to confirm that dilute $\mathrm{Cl}_{2}$ molecules in aqueous solution induce the oxidation of the $\mathrm{Si}$ surface and do not leave residual $\mathrm{Si}-\mathrm{Cl}$ bonds.

\section{Discussion}

This first series of experiments shows that the surface treatment of $\mathrm{Si}$ substrates by elemental chlorine solutions leads to the generation of a uniform chemical oxide layer. In this respect the data given by XPS measurements lead to unambiguous conclusions. The method seems very attractive, since many parameters such as concentration and temperature can be adjusted for an optimization of the oxide structure.

In order to interpret the mechanisms involved in this novel method in the frame of the electrochemical features in semiconductors, we used the model of charge transfer at the interfaces which has been developed by Gerischer ${ }^{25)}$ The model is based on the exchange between the carriers, $\mathrm{h}^{+}$or $\mathrm{e}^{-}$, in the semiconductor and the redox species in the solution following the formal equation:

$$
\begin{aligned}
J(\varepsilon)= & +\mathrm{e} \int \mathrm{v}^{+}(\varepsilon) N_{\mathrm{v}}(\varepsilon) D_{\text {red }}(\varepsilon) \mathrm{d} \varepsilon \\
& -\mathrm{e} \int \mathrm{v}^{-}(\varepsilon) N_{\mathrm{o}}(\varepsilon) D_{\text {ox }}(\varepsilon) \mathrm{d} \varepsilon
\end{aligned}
$$

where $\mathrm{v}^{+}(\varepsilon)$ and $\mathrm{v}^{-}(\varepsilon)$ are the frequency factors for the energy level $\varepsilon, N_{0}(\varepsilon)$ and $N_{\mathrm{v}}(\varepsilon)$ are the densities of occu- 
pied and vacant states in the semiconductor and $D_{\text {ox }}(\varepsilon)$ and $D_{\text {red }}(\varepsilon)$ are the state densities of electron acceptors and donor chemicals in the solution. This equation was established for a semiconductor in contact with only a single redox couple, such as the $\mathrm{Cl}_{2} / \mathrm{Cl}^{-}$couple whose standard potential is $E^{0}{ }_{1}=+1,358 \mathrm{~V}$ vs SHE. But a second redox reaction is involved for the generation of the surface silicon oxide. ${ }^{26)}$

$$
\begin{aligned}
& \mathrm{Si}+2 \mathrm{H}_{2} \mathrm{O} \Leftrightarrow \mathrm{SiO}_{2}{ }^{\text {hyd }}+4 \mathrm{H}^{+}+4 \mathrm{e}^{-} \\
& {E^{0}}_{2}=-0.84-0.059 \mathrm{pH}, \mathrm{V} \text { vs SHE }
\end{aligned}
$$

In fact, in our previous publication, ${ }^{27)}$ we pointed out that the silicon/electrolyte interface should be considered as a dual redox system involving two simultaneous electrochemical reactions. In this presentation, the silicon material is considered not only as an electron and hole reservoir, but also as a redox chemical component. This concept is now clearly supported by OCP results of Fig. 1 , where $\mathrm{p}$ - and $\mathrm{n}$-type $\mathrm{Si}$ samples behave identically and lead to the conclusion that they are both high purity silicon element.

The current density given by equation (3) approaches the Butler Volmer relationship ${ }^{28)}$ which can be written in the simplified form:

$$
j=-j_{01} \exp \left[-\alpha\left(E-E_{1}\right) / \phi\right]+j_{02} \exp \left[\beta\left(E-E_{2}\right) / \phi\right]
$$

where $j_{01}$ and $j_{02}$ are the exchange current densities at the cathodic and anodic sites, $\alpha$ and $\beta$ are the corresponding transfer coefficients, $E_{1}$ and $E_{2}$ are the equilibrium potentials for cathodic and anodic reactions, and $\phi$ is the thermal volt equivalent equal to $R T / F$ or $k T / e$. This equation shows similarities with eq. (3) in that the values of $j_{01}$ and $j_{02}$ are almost proportional to both the charge carrier density in the semiconductor and the concentrations of the donor/acceptor species in the solution.

The condition of zero current derived from eq. (4) leads to the OCP value which is also called mixed potential $E_{r}$ :

$$
E_{\mathrm{r}}=\left(\alpha E_{1}+\beta E_{2}\right) /(\alpha+\beta)+[R T / F(\alpha+\beta)] \ln \left(j_{01} / j_{02}\right)
$$

This expression describes the set up of a steady regime defined by the equalization of the oxidation and reduction currents, thus leading to the values of the corrosion current $j_{\text {corr }}$ and the polarization resistance $R_{\mathrm{p}}$ :

$$
j_{\text {corr }}=R T / F(\alpha+\beta) R_{\mathrm{p}}
$$

The rigorous interpretation of the OCP value and its variation must include the fact that it mainly reflects the relative variations of the exchange current densities $j_{01}$ and $j_{02 .}$. This explains the sudden shift of the OCP upon addition of the chlorine solution. However, only the ratio $j_{01} / j_{02}$ is important. This is the reason why the OCP value reaches rapidly a constant value although the structure of the oxide layer is changing continuously.
Then it is important to have the variations of $j_{01}$ and $j_{02}$ separately. This is obtained by the impedance diagrams also recorded at zero current values. From the diagrams presented in Fig. 4 and the numerical data of Table 1, we can see that the surface resistance $R_{\mathrm{p}}$ still increases with time although the OCP has reached a steady value in a few minutes. A first oversimplified interpretation could involve a continual growth of the oxide thickness which inhibits both the charge transfer and the material transport of reactants through the layer.

However, the XPS data indicate that the thickness of this oxide film reaches a constant value after a rather short time, i.e. a few minutes. A quite similar behaviour was observed in the $\mathrm{Si}$ oxide growth ${ }^{29)}$ after treatment with $\mathrm{SC} 1$ solution. In this case the layer resistance continually increased, while ellipsometric measurements revealed a constant thickness. Then, recording the ATR (attenuated total reflection) IR spectroscopy showed a gradual sharpening of the Si-O-Si longitudinal vibration mode, which led to the conclusion that the initial silanol -Si-OH groups were condensed into - $\mathrm{Si}-\mathrm{O}-\mathrm{Si}$ - bridges. The layer structure turns to be more compact and insulating so as to hinder the transport processes.

The mechanism of the charge transfer reactions should include the surface generation rate of carriers mainly by the highly oxidizing $\mathrm{Cl}_{2}$ reactants, and could be predicted from the following arguments: Firstly, the energy levels of electrons in the $\mathrm{Si}$ valence and conduction bands were known from literature data, ${ }^{303}$ and the Fermi levels of $n$ - and $p$ - type samples were evaluated from the dopant concentration in the semiconductor. On the other hand, the redox potential of both $\mathrm{Si}$ species and $\mathrm{Cl}_{2}$ solution were determined and positioned in the diagram referred to the absolute zero potential of vacuum $^{31)}$ using the value of $-4.31 \mathrm{eV}$ for the standard hydrogen electrode (SHE). When the semiconductor electrode and the solution are in contact, the Fermi level in silicon tend to equalize the solution mixed potential ${ }^{8)}$ defined by the dual redox system. The main result of this computation was that the electron energy level in the solute $\mathrm{Cl}_{2}$ molecules is extremely deep. So that the band positions in the diagram as well for a p-type and a n-type $\mathrm{Si}$ substrate are not much different each other in comparison with the large interval of energy between the Fermi level and the level in $\mathrm{Cl}_{2}$ molecules. The main feature of this band structure is that the charge transfer between $\mathrm{Cl}_{2}$ species and the substrate should take place with the valence band and involve $\mathrm{h}^{+}$holes in a large range of applied voltage for both $\mathrm{n}$ - and $\mathrm{p}$-type silicon.

$$
\mathrm{Cl}_{2} \Rightarrow 2 \mathrm{Cl}^{-}+2 \mathrm{~h}^{+}
$$

The generated holes $\mathrm{h}^{+}$drive the OCP to more positive values and promote the two step oxidation reaction :

$$
\begin{aligned}
& -\mathrm{Si}-\mathrm{H}+\mathrm{h}^{+} \Rightarrow-\mathrm{Si}^{\bullet}+\mathrm{H}^{+} \\
& -\mathrm{Si} \boldsymbol{H}^{\bullet}+\mathrm{H}_{2} \mathrm{O}+\mathrm{h}^{+} \Rightarrow-\mathrm{Si}-\mathrm{OH}+\mathrm{H}^{+}
\end{aligned}
$$

and finally:

$$
2-\mathrm{Si}-\mathrm{OH} \Rightarrow-\mathrm{Si}-\mathrm{O}-\mathrm{Si}-+\mathrm{H}_{2} \mathrm{O}
$$


All these transformations, and the related zero current electrochemical properties can be interpreted as surface reactions involving only surface states. This is the basic reason for which the behaviour of $\mathrm{p}$ - and $\mathrm{n}$-type $\mathrm{Si}$ substrates appeared almost identical. In the case of impedance spectroscopy, the only difference is that the n-type samples reveal the formation of a depletion layer $R C$ loop due to the positive polarization induced by the hole generation following reaction (7). A quite symmetric situation would be obtained with p-type $\mathrm{Si}$ if the sample was polarized with a negative bias potential. ${ }^{23}$

The interpretation of the current/voltage graphs is more delicate because the direct potential has to overcome the ohmic drop through the space charge region which is strongly dependent on the applied potential. The conditions of our experiments are quite different from those prevailing in other publications ${ }^{32}$ which involve fluoride or alkaline species and a strong etching of the $\mathrm{Si}$ substrate. In our experiments only a limited oxidation of the substrate takes place and form a highly resistive oxide layer extremely stable in the acidic medium. The understanding of the experimental results is obvious with the fundamental description of the space charge layer and the knowledge of the potential range for the depletion formation given in our recent publications. ${ }^{19}{ }^{232}$

In the case of p-type $\mathrm{Si}$ (Fig.2), the positive polarization creates a highly conducting accumulation layer which is in agreement with the sharp increase of oxidation current for $E>+0.4 \mathrm{~V}$ vs SCE. The curve was intentionally limited in this positive potential range to avoid a possible interference due to the rise of an anodic oxide.

When the bias potential is shifted to more negative than $E_{\mathrm{Cl}}$ potential values, the reduction current of $\mathrm{Cl}_{2}$ is quite negligible in the dark, although the $\mathrm{Si}$ space charge is in the situation of $\mathrm{h}^{+}$accumulation. This behaviour reflects the high resistance of the oxide surface layer, a few $M \Omega$, provided the electric field in the layer is not intense enough. At a potential of $-0.2 \mathrm{~V}$ vs SCE, the higher electric field in the oxide induces a rise of the reduction current revealing the appearance of a conduction mode attributed to tunneling or to a Fowler-Nordheim mechanism through the ultra thin insulating layer. ${ }^{33)}$ The interesting feature on the graph on Fig. 2 is that the reduction current reaches soon a plateau limited at -150 $\mathrm{nA} \mathrm{cm}^{-2}$. From our previous results, ${ }^{19,23)}$ such a low value can readily be assigned to the build-up of a depletion layer, a few $\mathrm{M} \Omega$ resistant, localized between the back side contact and the $\mathrm{Si} /$ electrolyte interface. The same interpretation holds for the limited reduction current of $\mathrm{Br}_{2}$ at a p-type $\mathrm{Si}$ surface observed by Bressers $e t$ $a l .{ }^{32}$ These authors indicated that their results were surprising since the cathodic current was much lower than that expected for a diffusion-controlled reaction.

In Fig. 3 the current/voltage graph for n-type $\mathrm{Si}$ is almost superimposed to that obtained with p-type $\mathrm{Si}$ in the range of potential between +0.4 and $-0.2 \mathrm{~V}$ vs SCE, and then it could be interpreted with the same outlines. But when the bias reaches -0.3 Volts the reduction cur- rent rises suddenly and could attain values as high as several $\mathrm{mA} \mathrm{cm}{ }^{-2}$. The main difference with p-type $\mathrm{Si}$ is that the space charge in $\mathrm{n}$-type $\mathrm{Si}$ corresponds to an accumulation highly conducting layer of electrons near the interface. An oversimplified interpretation would tend to assign this high reduction current of chlorine molecules to an electron transfer reaction. However, from the evaluation of the levels, as indicated hereupon, it seems that the potential $E_{\mathrm{Cl}}$ can hardly reach the n-type $\mathrm{Si}$ conduction band. Finally the real mechanism could be the injection of $\mathrm{h}^{+}$by reaction (7) at defect states within the oxide layer, these states being in turn neutralized by electrons from the n-type semiconductor. At this stage, it is useful to recall that a voltage as small as $0.5 \mathrm{~V}$ results in an electric field equal to $10^{7} \mathrm{~V} \mathrm{~cm}^{-1}$ when applied across an oxide layer $5 \AA$ thick. This appears to be the main difference with p-type Si substrate, because the formation of a depletion layer, about $250 \mathrm{~nm}$ thick as shown in our previous paper, ${ }^{19)}$ makes the electric field less than $10^{4} \mathrm{~V}$ $\mathrm{cm}^{-1}$ and explains the extremely low observed current.

\section{Conclusion}

For the first time an aqueous solution of elemental chlorine is used to grow a surface oxide on a silicon substrate. This novel technique opens new outlooks on the surface cleaning in the wet treatments for silicon processing in production lines. Among several advantages of the method, we can cite the high oxidizing potential of $\mathrm{Cl}_{2}$ for the chemical reaction with many contaminant species, the complexing and dissolving properties for a number of metals. The reactivity of $\mathrm{Cl}_{2}$ makes it very efficient for breaking the Si-H bonds, so that the oxidation proceeds uniformly and does not affect the surface flatness. Moreover this gaseous element is steadily eliminated on drying the wafers, and its compounds are volatile and disappear after heat treatment.

Diluted chlorine solutions, simply obtained by dissolving $\mathrm{Cl}_{2}$ in UPW, are very promising with respects to the economy and the environmental requirements. Naturally, the use other halogens such as $\mathrm{Br}_{2}$ or $\mathrm{I}_{2}$ could be developed. The reactivity of these species can be controlled by the selection of the element, the concentration, and the temperature. Thus it is possible to obtain an adjusted thickness with a more or less compact structure. These parameters being quite important in the subsequent thermal processing of the semiconductor, or for the growth of a high-k multi-layer structure.

\section{References}

1) F. W. Kern, Jr and G. W. Gale, in Handbook of Semiconductor Manufacturing Technology, Y. Nishi and R. Doering, Marcel Dekker Inc., N.Y., p.87 (2000).

2) W. Kern and D. A. Puotinen, Cleaning solution based on hydrogen peroxide for use in silicon semiconductor technology. RCA Reviews, 31, 187 (1970).

3) M. Meuris, S. Verhaverbeke, P. W. Mertens, M. M. Heyns, L. Hellemans, Y. Bruynseraede, and A. Philipossian, Jpn. J. Appl. Phys., 31, L1514 (1992).

4) T. Ohmi, M. Miyashita, M. Itano, T. Imaoka, and I. Kawanabe, IEEE Trans. Electron. Devices, 39, 537(1992). 
5) V. Bertagna, R. Erre, F. Rouelle, M. Chemla, S. Petitdidier, and D. Levy, Electrochim. Acta, 47, 129 (2001).

6) T. Ohmi, T. Isagawa, M. Kogure, and T. Imaoka, J. Electrochem. Soc., 140, 804 (1993).

7) A. Kazor and I. W. Boyd, Electronics Lett., 29, 115 (1993).

8) X. G. Zhang, Electrochemistry of Silicon and its Oxide, Kluwer Academic/Plenum Publishers, N. Y. (2001).

9) M. Miyashita, T. Tsuga, K. Makihara, and T. Ohmi, J. Electrochem. Soc., 139, 2137 (1992).

10) Y. H. Kim, M. Tuominen, I. Ranijmakers, R. de Blank, R. Wilhelm, and S. Haukka, Electrochem. Solid State Lett., 3, 346 (2000).

11) S. Haukka, E. L. Lakomaa, and A. Root, J. Phys. Chem., 97, 5085 (1993).

12) K. Kukli, J. Aarik, A. Aidla, H. Siimon, M. Ritala, and M. Leskela, Appl. Surf. Sci., 112, 236 (1997).

13) M. Chemla, S. Petitdidier, D. Levy, and F. Rouelle, French Patent, registered by STMicroelectronics SA, N ${ }^{\circ}$ 0308055, 02 July 2003.

14) M. Y. Jung, S. S. Choi, J. W. Kim, and D. W. Kim, Sur. Science, 482, 1119 (2001).

15) C. M. Aldao and J. H. Weaver, Progress in Surface Science, 68, 189 (2001).

16) W. Lin and H. Huff, in Handbook of Semiconductor Manufacturing Technology, T. Nishi and R. Doering Eds., Marcel Dekker Inc. p.35 (2000).

17) V. Bertagna, F. Rouelle, and M. Chemla, J. Appl. Electrochem., 27, 1179 (1997).

18) B. A. Boukamp, Equivalent Circuit version 4-51, University of Twente, The Nederlands (1993).

19) M. Chemla, V. Bertagna, F. Rouelle, S. Petitdidier, and D. Levy, Electrochemistry, 71, 844 (2003).

20) J. H. Scofield, J. Electron. Spectrosc., 8, 129 (1976).
21) V. Bertagna, F. Rouelle, G. Revel, and M. Chemla, $J$. Electrochem. Soc., 144, 4175 (1997).

22) V. Bertagna, R. Erre, F. Rouelle, D. Levy, S. Petitdidier, and M. Chemla, J. Solid State Electrochem., 5, 306 (2001).

23) M. Chemla, V. Bertagna, R. Erre, F. Rouelle, S. Petitdidier, and D. Levy, Electrochem. Solid State Lett., 6, G7 (2003).

24) F. J. Himpsel, F. R. Mc Feely, A. Taleb-Ibrahimi,, J. A. Yarmoff, and G. Hollinger, Phys. Rev. B, 38, 6084 (1988).

25) H. Gerischer, Electrochim. Acta, 35, 1677 (1990).

26) W. M. Latimer, The oxidation states of the elements and their potential in aqueous solutions, Prentice-Hall, Inc. Englewood Cliffs, NJ, p.144 (1961).

27) V. Bertagna, C. Plougonven, F. Rouelle, and M. Chemla, J. Electrochem. Soc., 143, 3532 (1996).

28) V. Bertagna, R. Erre, F. Rouelle, and M. Chemla, J. Electrochem. Soc., 146, 83 (1999).

29) S. Petitdidier, F. Guyader, K. Barla, D. Rouchon, N. Rochat, R. Erre, and V. Bertagna, in Cleaning technology in semiconductor device manufacturing VII, J. Ruzyllo, T. Hattori, R. L. Opila, and R. E. Nowack Eds, Electrochemical Society Proceedings Vol 2001-26, p.205.

30) M. X. Tan, P. E. Labinis, T. S. Nguyen, J. M. Kesselman, C. E. Stanton, and N. S. Lewis, in Progress in Inorganic Chemistry, Vol. 41 K. D. Karlin Ed., Wiley, N. Y., p.21 (1994).

31) A. J. Appleby, M. Chemla, H. Kita, and G. Bronoel, in Encyclopedia of electrochemistry of the elements, A. J. Bard Ed., M. Dekker, N. Y., Vol. 9, p.383 (1982).

32) P. M. M. C. Bressers, M. Plakman, and J. J. Kelly, J. Electroanal. Chem., 406, 131 (1996).

33) M. L. Green, E. P. Gusev, R. Degraeve, and E. L. Garfunkel, J. Appl. Phys., 90, 2057 (2001). 